\title{
Achieving Equitable Outcomes through Games: Using Board Games for Civic Engagement in Scenario Planning
}

\author{
Ming-Chun Lee, University of North Carolina at Charlotte, United States
}

\begin{abstract}
Scenario planning is a method that tests development alternatives and their impacts on achieving community goals. This planning method influences growth policy and development regulations and is useful in communications between different departments in the government and the subsequent trade-offs are significant to be able to communicate with the general public. City of Charlotte has been using scenario planning to work with local communities to develop the Charlotte Future 2040 Comprehensive Plan. The City is using a game called Growing Better Places to engage with residents and collect inputs for the Comprehensive Plan and for participants to learn about prioritizing growth and its impacts. The results of each game were combined to make three growth scenarios to show how Charlotte could grow. These scenarios in turn played a central role in assisting the City to adjust their general land use planning strategies. This study investigates those operational issues behind this game and the ability of the City to continually engage with local communities during the planning process.
\end{abstract}

\section{Keywords}

Scenario Planning, Civic Engagement, Comprehensive Plan, Board Games

\section{Introduction}

Scenario planning is a method that tests development alternatives and their influences on achieving community goals. It is mainly used by the government to support long-term well-being of the community. This planning method influences growth policy and development regulations and is useful in communications between different departments in the government and the subsequent trade-offs are important to be able to communicate with the community at large. Scenario planning that utilizes geographic information mapping to enable data analysis and facilitate communications has been frequently used in regional land use and transportation planning. One example is CONNECT Our Future, a regional plan completed in 2015 for the 14-county region around the City of Charlotte in the United States. Charlotte's current comprehensive planning project, the Charlotte Future 2040 Comprehensive Plan, is also using scenario planning as a way to develop alternative plans for comparisons and dialogues.

The City of Charlotte has been partnering with local communities to develop the Charlotte Future 2040 Comprehensive Plan, a plan that will guide how the city will invest in itself over the next 20 years. Once adopted, the plan will be the foundation for strategic policy, equitable investment in infrastructure, and new regulatory tools. It will be the blueprint for the City of Charlotte to realize its vision, which is aimed to opening its arms to a diverse and inclusive community of residents, businesses, and visitors alike; a safe family-oriented city where people work together to help everyone thrive. 
The City of Charlotte is using a board game called Growing Better Places in their current Charlotte Future 2040 Comprehensive Plan process to engage with residents and collect inputs for the Comprehensive Plan and for participants to learn about prioritizing and leveraging growth and its impacts. The community inputs collected during these games have also been fed into the City's scenario analysis for developing various future growth alternatives for comparisons and negotiations. One key objective of this game is to ensure that the path to creating complete neighborhoods for all residents in the city is equitable, economically viable and fiscally responsible.

This study seeks to investigate what operational issues behind this game have an effect on the effectiveness and the ability of the city to continually engage with local communities during the Charlotte Future 2040 Comprehensive Plan process. In particular, this study examines the pros and cons of this approach with regard to bridging the gap of under-representation by African Americans, youth, Hispanics, Latino, and senior citizens. This study also compares the various ways in which this board game is played (online vs. in-person) and attempts to identify best practices that can achieve the game's main goal, which is to listen and engage with all communities in Charlotte.

\section{Charlotte Future 2040 Comprehensive Plan}

The Charlotte Future 2040 Comprehensive Plan is being developed in four phases (City of Charlotte, 2019a):

- Phase 1: Existing Conditions and Trends Assessment. This phase is about collecting information and listening to the people about what they want their communities to look like over the next 20 years, and the goals they need to set to make that happen.

- Phase 2: Growth Scenarios and Place Types. This phase will take a look at the ways Charlotte could grow and determine the trade-offs of each way to determine the preferred option to make the city's vision a reality.

- Phase 3: Framework and Plan Elements. This phase will start to draft the actual plan with needed supporting policies that will guide the city's growth. This phase will also start to look at the steps the city will need to take to make following through on the plan a reality.

- Phase 4: Final Plan and Adoption. In this phase, final reviews will be conducted. City Council will be asked to adopt the plan and use it to guide their decisions.

As of March 2020, the first two phases of the project have been completed. Phases 1 and 2 in the Comprehensive Plan process, which lasted from winter 2018 to fall 2019, were spent engaging with the community to discover their values and priorities for the city's future. During 2019, the Charlotte Future 2040 Comprehensive Plan team worked to develop a set of vision elements and goals based on the inputs from over 4,500 Charlotte residents. From these inputs, three guiding principles emerged that help shape the Comprehensive Plan as it looks to the future: Authentic, Equitable, and Integrated. Each vision element looks ahead to the Charlotte of 2040 and strives to integrate these three concepts. The Charlotte Future 2040 Comprehensive Plan is currently in Phase 3, which will last until the end of fall 2020 and focus on the introduction of policies and strategies that will fulfill the city's values, vision, and goals. The Charlotte Future 2040 Comprehensive Plan is on schedule to be adopted by the Charlotte City Council in early 2021 (City of Charlotte, 2019a). 


\section{Research Questions and Research Methods}

This study is concerned with the factors that are attributed to the implementation of the Growing Better Places board game. In other words, this study attempts to unfold what operational issues have an effect on the effectiveness and the ability of this game to continually engage with local communities during the Charlotte Future 2040 Comprehensive Plan process. In particular, this study examines the pros and cons of this approach with regard to bridging the gap of under-representation by African Americans, youth, Hispanics, Latino, and senior citizens. This study also compares the various ways in which this board game is played (online vs. in-person) and attempts to identify those best practices that can achieve the game's main goal: listening and engaging with all communities in Charlotte. This study is also concerned with the role(s) city staff can play in the implementation of this game.

The proposed study falls into the qualitative inquiry category. The phrase "qualitative inquiry" refers in the broadest sense to research that produces descriptive data, including people's own written or spoken words or observable behavior. Qualitative researchers tend to look at the context of study and the participants as a whole. It is an inductive process in that researchers gain insight and a deeper understanding through patterns in the data.

This study is carried out by the comparative case study research method, which is one of several ways of doing case study research. Comparative case studies make use of multiple cases for the purpose of comparison.

Four data collection techniques will be employed in this study: 1) documentation review; 2) surveys; 3 ) interviews; and 4) on-site observations and informal conversations with game players and city staff.

- Documentation review: a review of official documents or status reports of the Comprehensive Plan process will be conducted.

- Surveys: for the past game workshops in Phase 2, player survey records collected by city staff will be reviewed. For the next round of Growing Better Places board game planned for Phase 3, a survey will be prepared and distributed to game managers to collect information about the game operation and results from the players.

- Interviews: a semi-structured interview with game managers and selected game players will be conducted. The primary goal of the interview will be to gather information regarding the effectiveness of the board game in reaching out to under-represented participants and raising players' awareness of development options that can achieve an equitable growth pattern.

- On-site observations and informal conversations with game players: on-site observations will be conducted during the next round of board games in Phase 3. Informal conversations with players will be carried out to collect viewpoints about the play experience from users' perspectives.

\section{Scenario Planning}

Over the past three decades, scenario planning with its visioning techniques has helped planners and citizens to articulate priorities and values and help shape the future of their metropolitan regions. It is through scenario planning that the question of what the future might look like can be narrowed down to a more manageable set of possibilities (Lee, 2016).

A scenario is an internally consistent view of what the future might turn out to be. It is not a forecast, but one possible future outcome (Ringland, 1998; Bartholomew \& Ewing, 2008). Fundamentally, scenarios 
are stories about the future (Ogilvy, 2002). They cannot predict the future precisely. Rather each should only present a vision of the future that is plausible in light of known information (Ringland, 2002).

According to Bartholomew (2007) and Smith (2007), the origin of scenario planning can be traced back to the RAND Corporation (Kahn, 1962) in the 1950s, during which scenario planning was used as a way to consider multiple aspects of a problem at the same time. It was considered as a technique to help strategic planners with limited backgrounds and resources to address the uncertainty embedded in decision-making. It facilitated creative thinking allowing imaginations about how a future might unfold (Andrews, 1992; Bradfield et al, 2005; Chakraborty et al, 2011).

The regional land use-transportation scenario planning practice that emerged in the 1990s basically implanted the military and business models into routine planning practices of the so-called $3 \mathrm{C}$ process (continuing, cooperative, and comprehensive) that was required by the Federal Highway Act of 1962, and the environmental impact assessment requirements by the National Environmental Policy Act (Bartholomew, 2007; Bartholomew \& Ewing, 2008)

A typical land use-transportation scenario planning process compares one or more alternative future development scenarios to a trend scenario. In the trend scenario, both land development and transportation investment patterns of the recent past are assumed to continue to a planning horizon of 20-50 years in the future and the impacts of this trend on the region and its transportation infrastructure are assessed. This is followed by the formulation of one or more alternative scenarios that differ from the trend with respect to land use choices and transportation investments. These alternative scenarios are then assessed for their impacts using the same set of outcome measures that were used to analyze the trend scenario (Bartholomew \& Ewing, 2008). Essentially, land use-transportation scenario planning assumes that if planners and decision makers consider multiple future scenarios and evaluate trade-offs by comparing their costs and effects, they are more likely to make better decisions.

\section{Civic Engagement with Board Games}

An equitable planning process can produce a comprehensive plan and policies that guide any government in making strategic and equitable decisions on topics including infrastructure investments, affordable housing, and guidance for private sector development, etc. With this belief in mind, the City of Charlotte is committed to listening to the voices of all citizens. African Americans, youth, Hispanics, Latino, and senior citizens are groups who have typically been less engaged in past planning efforts. To ensure an equitable and fair planning process, the Charlotte Future 2040 Comprehensive Plan team has been constantly conducting community engagementactivities. Throughout each phase of creating the Charlotte Future 2040 Comprehensive Plan, the approach has been varied, inclusive, and diverse. Among all these community engagement activities, a special board game, called Growing Better Places, has been the key instrument employed by the city to reach out to the local communities, especially for those who have been under-represented in the past (City of Charlotte, 2019b).

In summer and fall 2019 during Phase 2 of the Comprehensive Plan process, Charlotte citizens played Growing Better Places, a board game designed for city staff to gather feedback for the Comprehensive Plan and for participants to learn about prioritizing and leveraging growth and its impacts. The purpose of the game is to gather inputs from a diverse cross section of the community about the future of Charlotte and to have fun doing it. Over 1,800 people have played the game online or in person at community meetings.

The key objectives of playing and winning the game include the following (City of Charlotte, 2019b): 
- Fill existing gaps in infrastructure and amenities that make several of Charlotte's neighborhoods incomplete today.

- Ensure that new development results in community benefits for existing and new residents and neighborhoods align with the community values expressed throughout Phase 1 of the Comprehensive Plan process.

- Allocate the projected number of housing units and jobs for Charlotte in 2040.

- Ensure that the path to creating complete neighborhoods for all citizens is equitable, economically viable and fiscally responsible.

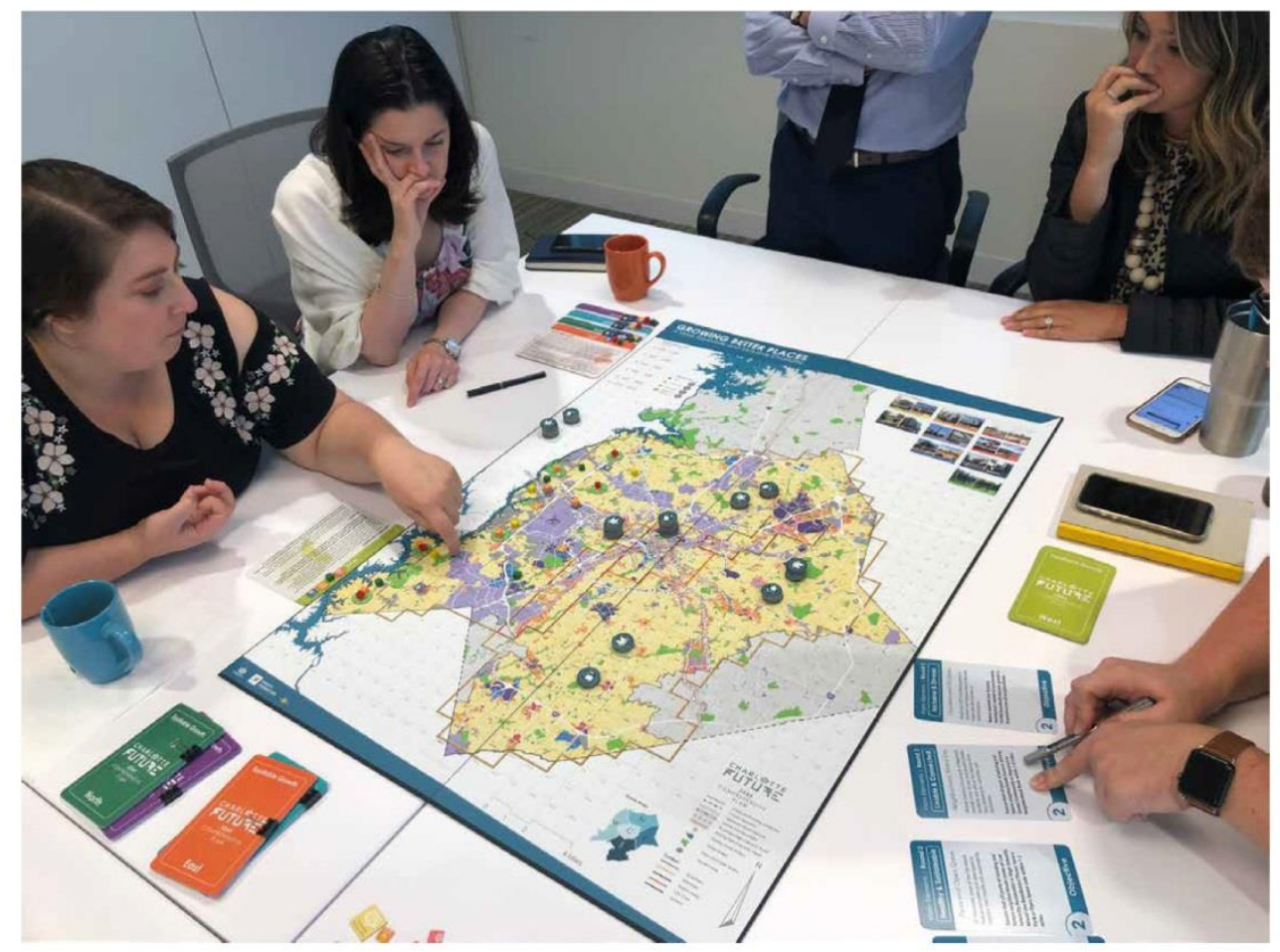

Figure 1. A typical set-up for Growing Better Places Board Game (Source: City of Charlotte).

\subsection{Game Overview}

The goal of playing the Growing Better Places game is to better understand the needs and impacts of growth and community changes citywide. The game is organized into two rounds. Participants can play just the first round if they choose or time is limited.

In Round 1, participants get familiar with each area of the City of Charlotte, including what is there today, what is missing to make certain neighborhoods more complete, what the current projections for growth are across the city, and how the Comprehensive Plan can integrate strategies to help achieve the community's vision.

In Round 2, participants can do a deeper dive into one or more areas of the city to fill gaps in existing infrastructure and amenities, provide inputs on where investments are made and help shape how and where Charlotte grows in the future. To win the game, participants must use Place Types to complete all of the required actions for a particular area and achieve the community's vision by ensuring strategies selected in Round 1 are fully implemented. 


\subsection{Place Types}

In 2015, the CONNECT Our Future Regional Growth Framework was completed for 14 counties surrounding the City of Charlotte in North and South Carolina. Based upon the inputs of 8,400 participants, a preferred growth concept for the region was created using a palette of 31 Place Types. Place types better represent how cities work and allow the community to shape more than just land use. Place types do address land use, but also include guidance for other elements, such as general area characters, transportation and parking, parks and open space, building heights, massing and frontages, and aspects of site planning, etc. For the Growing Better Places game, a set of nine Place Types are used to summarize existing conditions and to indicate how and where the community would like the City of Charlotte to grow (City of Charlotte, 2019b).
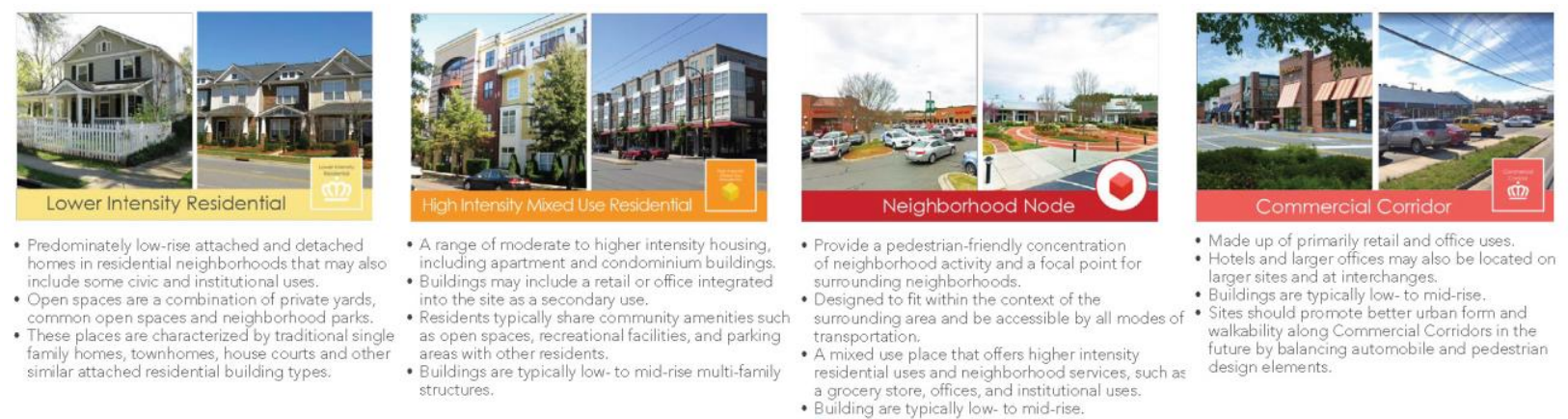

Figure 2. Examples of Place Types used in the Growing Better Places game (Source: City of Charlotte).

\subsection{Vision Elements and Goals}

During Phase 1 of the Comprehensive Plan process, citizens who participated in public meetings shared their passion, ideas, and values for the City of Charlotte. Starting with Vision and Values from earlier planning efforts, participants provided feedback and suggested additional ideas. These were used to confirm the Vision Elements and develop the top eight goals that the Comprehensive Plan can influence. This Growing Better Places board game integrates the vision elements and goals in Rounds 1 and 2 of the game. In addition, to ensure that these vision elements can be accomplished in an equitable way, the Growing Better Places game introduce a unique method to use Equitable Growth Cards to guide the players to explore equitable options in order to achieve the direction indicated by the overall Vision Element Objectives (City of Charlotte, 2019b).

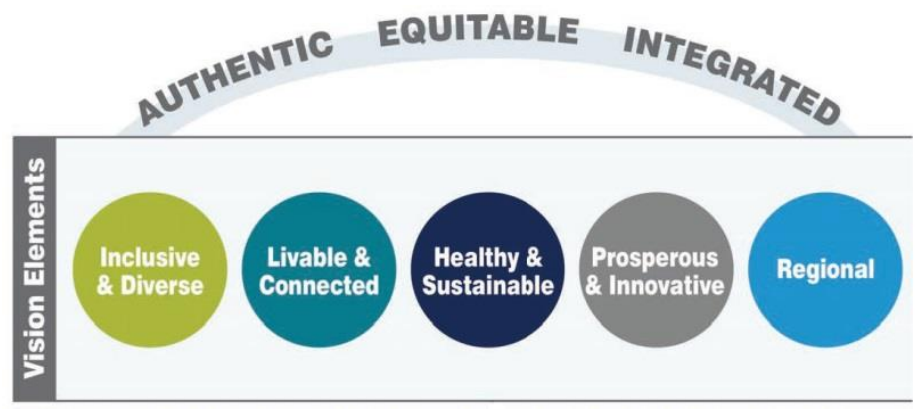

Figure 3. Vision Elements used in the Growing Better Places board game (Source: City of Charlotte).

\section{Growth Scenarios}

A key piece of comprehensive planning for the future growth of Charlotte in an equitable and inclusive way is the creation of Growth Scenarios. Starting with community inputs from the Growing Better Places 
game, a carefully calibrated, Charlotte-specific computer model using CommunityViz, a GIS-based mapping program, is developed to map and to analyze the likely impacts of different growth and development patterns. Four distinct scenarios, explained below, were created to better understand the trade-offs of citizens' choices. The results will help the City of Charlotte make more informed decisions about Charlotte's future (City of Charlotte, 2019c).

The four growth scenarios include the following:

- Business as Usual: Continues current growth patterns with strong growth in Center City and along key transit and transportation corridors.

- Strong Centers: Most development is in Regional Activity Centers, with at least one center in each of the six geographies to provide jobs, goods, services and community gathering spaces.

- Connected Corridors: This development creates strong corridors with an emphasis on transit station areas, neighborhood connections and trail systems. Community Activity Centers along the corridors provide jobs, goods, and services.

- Neighborhood Nodes: Numerous mixed use small scale centers offer goods and services close to neighborhoods. Additional residential intensity takes place near these smaller centers with less emphasis on transit stations and larger centers.
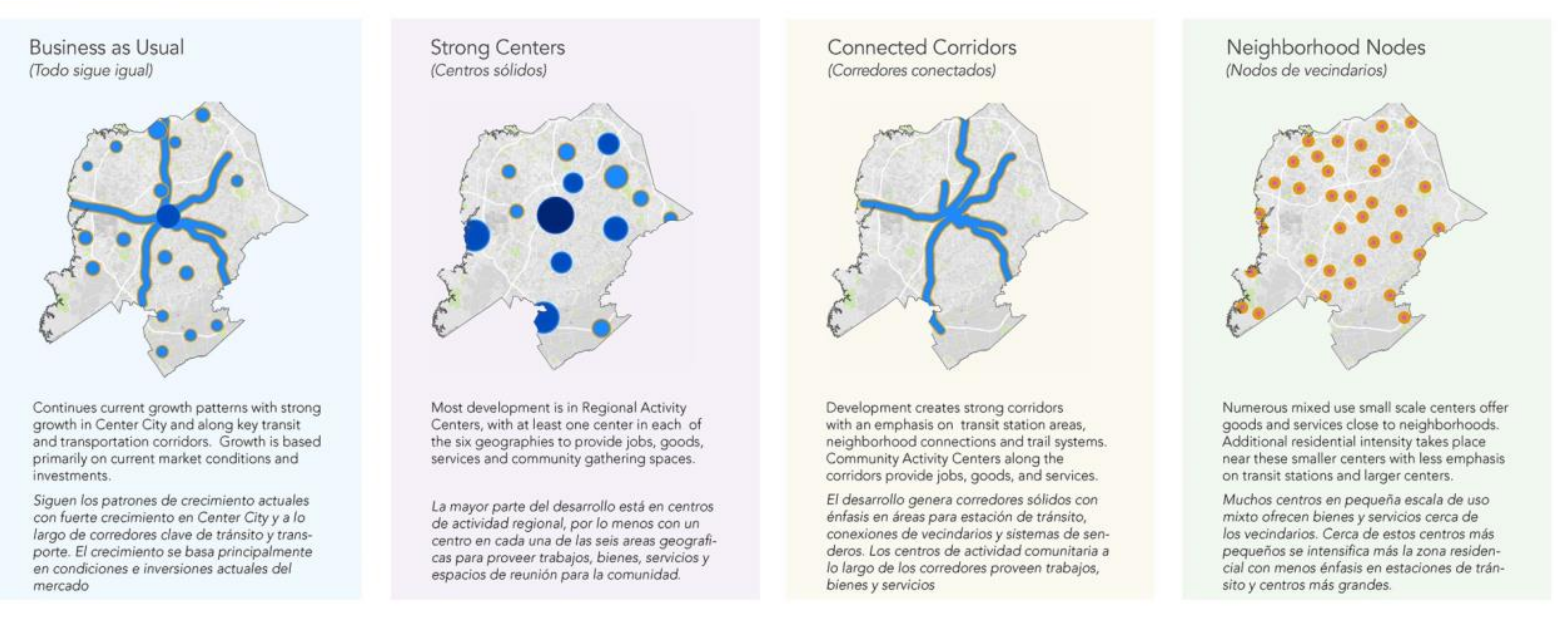

Figure 4. Four growth scenarios identified to better understand the trade-offs of citizens' choices (Source: City of Charlotte).

\section{A Preliminary Discussion of the Game Outcome}

\subsection{Game Data}

Over 1,800 Charlotte residents have played Growing Better Places board game between July and August 2019, including more than 840 people participated in several in-person community workshops and more than 990 people played the online version of the game. In addition to the actual game-playing activities, there have been more than 44,400 views of Board Game online content, including digital flyers, announcements, Facebook promotions, and emails.

\subsection{Demographics of Players}

Among these $1,800+$ players, $64 \%$ of participants identified themselves as White, $28 \%$ as Black, and $4 \%$ as Asian. Overall, $7 \%$ of participants also identified themselves as Hispanic/Latino. In terms of age, $62 \%$ of 
participants were between 25 and 44; while 38\% were 45 and above. In terms of income, 15\% of participants had annual income less than $\$ 49,000 ; 36 \%$ between $\$ 50,000$ and $\$ 100,000 ; \$ 49 \%$ more than $\$ 100,000$ (Figure 5).
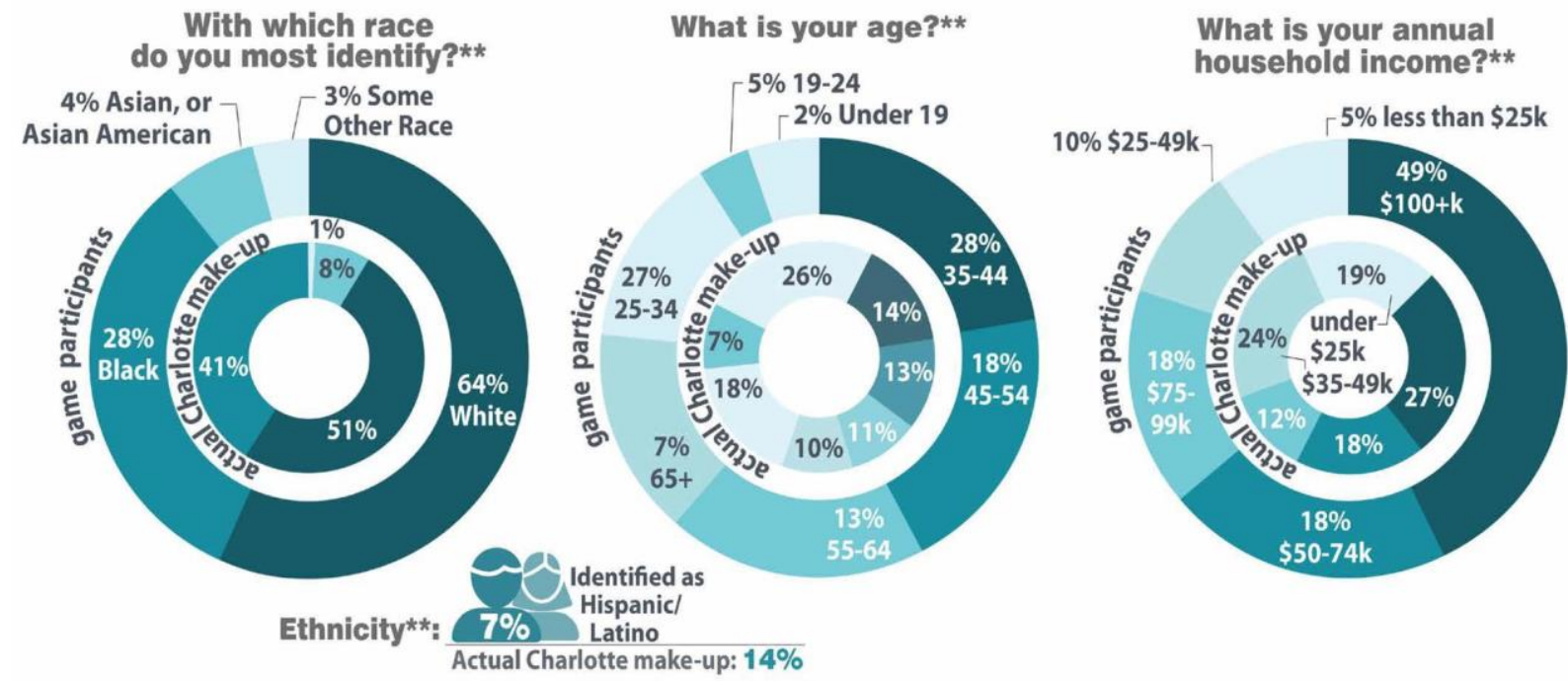

Figure 5. Demographics of participants in Growing Better Places board game (Source: City of Charlotte).

\subsection{Game Results: Mapping Agreement}

The results of each game were combined to make three growth scenarios to show how the City of Charlotte could grow. Based on all of the game plays, the composite results show growth on every square that players chose (Figure 6). These results show a number of common themes (City of Charlotte, 2019d):

- $\quad$ Reinforce existing pattern of growth

- More development in West and Center of the City

- Less development in South

- Follows transit and activity centers in East and North

- Well distributed neighborhood nodes in all geographies

\subsection{Next Steps for Charlotte Future 2040}

The Charlotte Future 2040 Comprehensive Plan is currently in Phase 3. In the next few months there will be several community engagement events, as well as community workshops focusing on Place Types and using Growing Better Places board game again to cross-examine the four growth scenarios in a hope that a preferred scenario can be identified by the end of Phase 3.

\section{Discussion and Conclusion}

As discussed earlier, map-based scenario planning seeks to booster the technical efficiency of spatial analysis in regional planning as well as to build transparent channels for communications and open platforms for participations necessary for the planning process. This socio-technical perspective is important to understand the significance of this particular type of planning, which seeks to integrate social practices of planning with information and communication technologies. 


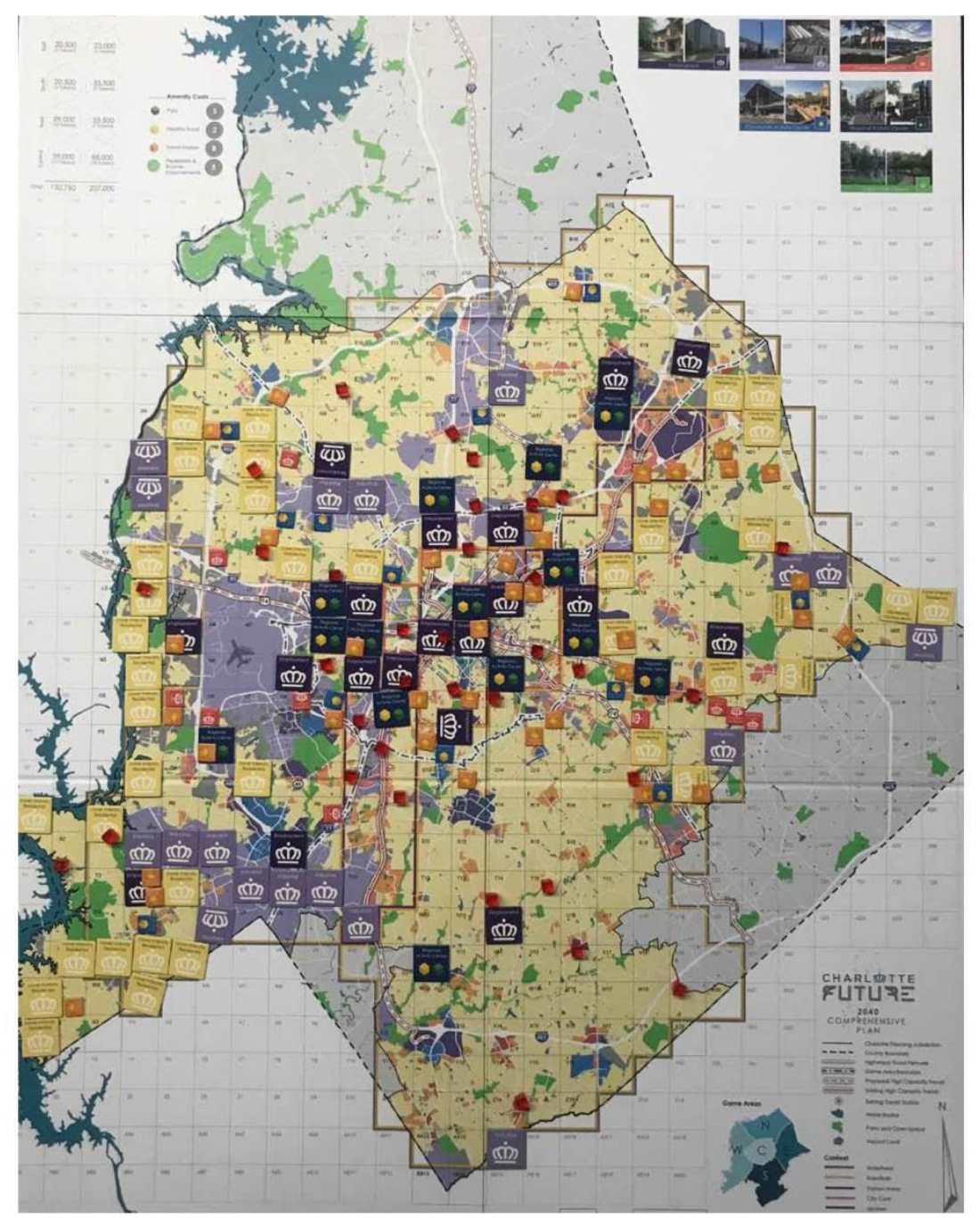

Figure 6. The composite results of the Growing Better Places board game (Source: City of Charlotte).

The Growing Better Places board game, discussed in this paper, is essentially a simplified paper-map version of this type of map-based scenario planning practice. It is again through this particular sociotechnical viewpoint that three key final observations about the Growing Better Places board game are drawn as the follow:

- Scenario planning enables rational inquiry and increases understandings of socio-economic systems.

The ability of these map-based techniques to conduct analyses and to illustrate the results of such analyses substantially increases planners' ability to engage and educate the general public about the rational aspect of various key factors involved in the planning process.

- Scenario planning allows collaborative actions and enables quick explorations and performance evaluations on planning alternatives

Scenario planning tools allow community members to generate and compare various land use scenarios that represent different policy alternatives. The Growing Better Places board game, with its map as the canvas, provides the participants a simple sketching interface to quickly paint different combinations of 
development alternatives, which can then be tested and refined based on identified parameters to produce a more sustainable solution that reflects the consensus among the community members participating in this collaborative process.

\section{- Scenario planning helps identify community values and promotes social learning}

The continuous public engagement and public education about the potential benefits of alternative growth strategies help build durable, inclusive consensus within the community over time. Various techniques used in this Growing Better Places board game, including Place Types, Vision Elements, and Equitable Growth Cards, all afforded the participating residents the opportunities to express their concerns, raise issues facing their respective community, and together identify key values that are essential to the future of their communities.

\subsection{Final Note}

Due to the on-going COVID-19 pandemic, the research activities that were originally planned have been disrupted. Those data collection events that may have required in-person contact were cancelled, including participant interviews and on-site observations of game-plays. The author of this paper plans to resume all research activities in the near future once the public health condition improves and proper authorizations are granted.

\section{Acknowledgement}

The author of this paper would like to thank the planning staff in the City of Charlotte for their assistance in getting access to some of the materials for this study.

\section{References}

Andrews, C.J. (1992). Sorting out a consensus: Analysis in support of multiparty decisions. Environment and Planning B: Planning and Design, 19 (2): 189-204.

Bartholomew, K. (2007). Land use-transportation scenario planning: promise and reality. Transportation, 34 (4): 397-412.

Bartholomew, K. \& Ewing R. (2008). Land Use-Transportation Scenarios and Future Vehicle Travel and Land Consumption: A Meta-Analysis. Journal of the American Planning Association, 75(1): 13-27.

Bradfield, R., Wright, G., Burt, G., Cairns, G. \& van der Heijden, K. (2005). The origins and evolution of scenario techniques in long range business planning. Futures, 37 (8): 795-812.

Chakraborty, A., Kaza, N., Knaap, G.-J. \& Deal, B. (2011). Robust Plans and Contingent Plans. Journal of the American Planning Association, 77 (3): 251-66.

City of Charlotte (2019a). Charlotte Future 2040 Comprehensive Plan, Project Overview,

https://charlottenc.gov/charlottefuture/2040plan/Pages/default.aspx (accessed 08-29-2020).

City of Charlotte (2019b). Charlotte Growth Game, https://charlottenc.gov/charlottefuture/2040Plan/Pages/GrowthGame.aspx (accessed 09-292020). 
City of Charlotte (2019c). Charlotte Growth Game Results, http://ww.charmeck.org/Planning/CompPlan/Boards/04_Game\%20Results.pdf (accessed 09-292020).

City of Charlotte (2019d). Scenario Overview, http://ww.charmeck.org/Planning/CompPlan/Boards/06_Scenario\%200verview.pdf (accessed 09-29-2020).

Kahn, H. (1962). Thinking about the unthinkable. Ann Arbor, MI: University of Michigan Press.

Lee, M.-C. (2016). Geodesign Scenarios, Landscape and Urban Planning, Special Issue: GeoDesignChanging the World, Changing Design, 156 (2016), p.9-11.

Ogilvy, J. (2002). Creating better futures: Scenario planning as a tool for a better tomorrow. New York: Oxford.

Ringland, G. (1998). Scenario planning: Managing for the future. New York: John Wiley.

Ringland, G. (2002). Scenarios in public policy. New York: John Wiley.

Smith, E. (2007). Using a scenario approach: From business to regional futures. In L. D. Hopkins \& M. A. Zapata (Eds.), Engaging the future: Using forecasts, scenarios, plans, and projects (pp. 79-101). Cambridge, MA: Lincoln Institute of Land Policy. 